\title{
IIRTBT THE IMPACT OF COVID-19 PANDEMIC LOCKDOWN ON THE MIGRANT LABOUR CRISIS AND CARDAMOM HARVEST IN HIGH RANGES OF KERALA
}

\author{
Navaneeth Krishnan S. \\ Centre for Historical Studies, Jawaharlal Nehru University, New Delhi, India \\ *Corresponding Author's Email: aachi1528@gmail.com
}

\begin{abstract}
This paper analyses the situation of cardamom planters and plantations against the backdrop of COVID-19 pandemic and lack of migrant labor during the harvesting season. The global pandemic resulted in large scale exodus of migrant labor across India. For more than a decade, the cardamom plantations in high ranges of Kerala depended on large-scale migrant labor force for weeding, manual irrigation, spraying of pesticides and fertilizers, and handpicking cardamom cloves. As the cultivation of cardamom is highly labor intensive, the scarcity of labor force resulted in large scale decay of unplucked cardamom cloves in various plantations. The shortage of labor force also resulted in a drastic increase in labor cost for hand picking of cardamom cloves from the plants. The cardamom is harvested around four times a year, but the initial harvest during the ongoing pandemic witnessed a fall in the price. This study focuses on unstructured interviews and conversations with large scale and small-scale planters, labourers, cardamom traders and people employed in commercial large scale drying of cardamom. The findings suggest that many cultivators organized various strategies to overcome the migrant labor crisis such as employing unskilled labourers at a high cost, bringing migrant labourers from their hometowns in private buses at the expense of cultivators. The migrant labor crisis also provided an employment opportunity for many people who lost their livelihood during the lockdown. The attempt here is to look at the larger transformation from below and contextualize the local transformations in the larger economic milieu.
\end{abstract}

Keywords: Cardamom; Kerala; Labor; Plantations

\section{INTRODUCTION}

The territorial spread of cultivation of small cardamom or Elettaria cardamomum in Kerala is mostly confined to Idukki, Wayanad and Palakkad districts. The cardamom hills of Idukki district produce the major share of the cardamom in markets of Kerala. This study attempts to highlight the issues of migrant labor crisis in the cardamom hills of Idukki district against the backdrop of COVID-19 pandemic lockdown. This study employs a descriptive research design and consults previous works related to cardamom cultivation in Idukki district. Also, this research analyses unstructured interviews of permanent and temporary labourers, managers, planters, local traders, and workers of cardamom dyers to uncover the experiences of individuals engaged in the production process of cardamom during the pandemic crisis.

In antiquities, people plucked cardamom cloves from various species of cardamom plants grown in the forest undergrowth and plants could regenerate naturally. Therefore, in antiquities, the labor force might have been necessary merely for harvesting and occasional weeding (Aiya, 1906). In those days, hill tribes of Western Ghats might have been the labor force behind harvesting of cardamom (Lovatt \& de Jong, 1993). The second half of the nineteenth century saw widespread deforestation and development of plantations of tea, coffee, and cardamom. Then most of the labor force in plantations constituted Tamils from then Madurai district of Madras Presidency. In the twenty-first century, the high economic growth and industrialization in Tamil Nadu along with employment opportunities abroad resulted in a decline in the number of Tamil youths working as cardamom plantation labourers. Despite a decrease in the number of Tamil labor force in cardamom hills, Tamils still constitute the majority of cardamom plantation labor. But the gradual decline in the number of Tamil labourers resulted in a labor shortage in large (above two acres), medium (fifty cents to two acres) and small (less than fifty cents) plantations.

In valley areas of Kerala, the primary labor force constitutes migrant workers from North and North-East India. The workers from North India mostly engaged in the construction, paddy harvesting and various menial 
jobs, whereas workforces from North-East India are employed in comparatively well-paid service sector jobs. The scarcity of labor force in cardamom and tea plantations provided new opportunities for migrant workers from North India. The large cardamom plantations usually comprise of many permanent Tamil labourers and temporary migrant workers. Whereas in medium and small plantations encompass more temporary migrant workers and less or no permanent Tamil or Malayali labourers.

The cultivation of cardamom as plantation crop is highly labor intensive as it has all the year-round activities. Since cardamom plants are grown on the slopes of mountains, it requires everyday irrigation during summer season (January to May). The workers water the plants with water pumped by diesel motor from streams or well by using hoses or by operating sprinklers. The workers weed the planation at least thrice a year and maintain a compost pit in the middle of every four cardamom plants. In summer, weeds plucked by workers are used to cover the bottom parts of the plants that lie above the soil to protect new buds from the summer heat. In summer months, managers allot specific areas of a plantation to each migrant worker for manual tilling of topsoil with shovels, picks and hoe. The large-scale manual tilling aerates the soil and benefits manual irrigation and manuring.

The plants are sprayed with insecticides every month to prevent the attack of shoot borers, stem borers and other small pests. The habitat of cardamom plants requires some amount of shade provided by tall forest trees, but when the trees are overgrown, it might also affect the rate of photosynthesis of cardamom plants. Therefore, the plantation workers occasionally cut a few branches from the top part of the tall trees to provide sufficient sunlight for plants. As mentioned earlier, Cardamom hills where once natural forests were cardamom plants grew naturally as undergrowth beneath the shades of giant trees. The abundant fauna of Western Ghats regularly raids cardamom plantations. The Wild Boars are known for digging out and eating the underground shoot of cardamom plants; similarly, a troop of monkeys are known for regularly feasting upon tender buds of cardamom plants. Consequently, the labourers also have to chase away wild animals that feast on crops regularly. Dogs are reared in some plantations to chase wild animals away from plantations.

The cardamom cloves are harvested from plants at least four times a year from June to December, which is roughly a period of seven months of a year. Cardamom cloves are gathered with a gap of forty to fifty days after every harvest. If not harvested in proper time, cloves might overripe and burst. It might take a lot of time to gather cardamom a large or medium plantation by very few permanent workers; therefore, migrant workers are widely employed to harvest cardamom. The unskilled temporary migrant workers initially receive the training of permanent workers to harvest the cardamom. The permanent workers are usually the residents from the locality of plantations, so they travel from their homes to close by plantations to complete their daily chores for livelihood. Unlike permanent labor, accommodations for migrant workers are provided by plantation owners or managers. The salary of migrant labourers is less compared to a permanent labourers, yet their wages are better than the wages received for similar jobs in villages of North India.

\section{LITERATURE REVIEW}

The findings of Aiya (1906) mention about cultivation and harvest of cardamom in the high ranges of Kerala before the onset of plantations in the second half of the nineteenth century. The work is devoid of the nuances of plantations agriculture in a major part of the twentieth century. Lovatt \& de Jong (1993) provide history of deforestation and emergence of plantations in Idukki, but the nuances on labor in plantations are beyond the scope of their study. The research of Ravindran \& Madhusoodanan (2002) is limited mostly to the botanical study of Cardamom. The economic studies of cardamom cultivation, such as the studies of Mathew \& James (2017) and Varghese (2007) reveal a literature gap as they have not studied the economic and social changes due to the COVID-19 pandemic. Similarly, the study by Anju \& Kumar (2020) analyses the agricultural practices and educational status of cardamom cultivators, but the nuances on labor shortage and impact of COVID-19 pandemic lockdown on cardamom economy is not covered.

\section{METHODLOGY}

To scientifically investigate the issues faced by the cultivators and labourers of cardamom plantations, unstructured interviews were conducted. The sampling universe of this study includes cardamom plantation workers, managers, owners, commercial cardamom dryers and local cardamom traders of Idukki District, Kerala, India. Twenty plantation workers that include five permanent and fifteen temporary workers responded to the unstructured interview. Apart from workers, two plantation managers, a Kangani, a commercial dryer manager, two plantation owners, and a local trader also responded to the interviews. The interviews were conducted mostly in the working hours of plantations. With the consent of workers themselves 
and managers and owners, the interviews were conducted in the buildings situated within the plantations. Following the safety measures during the pandemic, conversations with respondents were recorded by note-taking. The photographs were taken in the field with the consent of participants. A descriptive analysis approach is employed for data analysis.

\section{RESULTS \& DISCUSSION}

In Idukki, the location of many of the cardamom plantations is in areas inaccessible by vehicles. The unskilled migrant workers are employed to carry cardamom extracted on that day as headload and load them into a transport vehicle parked in a convenient location. After completing all four rounds of harvests, the dried parts of the plants are carefully removed and dumped to the compost pit.

Upon interviewing a few successful planters of Shanthanpara Panchayath in Idukki, they informed that hybrid variety cardamom plants in most of the plantations are replanted after ten years. In the past, they replanted plantations after fifteen years for traditional varieties of cardamom. For replanting, migrant workers are widely employed to clear old plants, tilling the soil, and making pits to plant saplings of cardamom purchased from local nurseries. Since replanting is a large-scale operation, migrant workers are widely employed alongside Tamil labourers to plant a single sapling in each pit. The workers carefully plant saplings in such a way that only roots are below the surface. In the initial days, workers tie saplings to wooden posts as a support to prevent them from falling. In two months, the root of the saplings grows firmly, after that workers provide neem cake and other organic fertilizers to saplings.

As per an experienced planter S. Karunakaran of Shanthanpara, it takes three years for the cardamom crops to provide yield, and the yield becomes stable from the fifth year to the eighth year. According to Karunakaran, for the last ten years, the labor of migrant workers was crucial in running his plantation. The COVID-19 pandemic outbreak in the early months of 2020, resulted in the government of India declaring nation-wide lockdown on $24^{\text {th }}$ March 2020. The enforcement of COVID-19 protocol resulted in the suspension of all activities in plantations of cardamom hills. The initials months of lockdown witnessed the mass departure of migrant workers from cities like Delhi, where workers travelled for days on foot to reach their homes. In Kerala, the enforcement of lockdown was so strict that workers could not assemble on the streets because of frequent police patrols. Later, the negotiations between the government of Kerala and central government resulted in arranging railway transportation for migrant workers. The strict lockdown resulted in bewildering most of the medium and large plantations up till the onset of COVID-19 unlock protocol on $8^{\text {th }}$ June 2020 .

The days of strict lockdown coincided with the months of monsoon in Kerala. Therefore, the planters managed without regular irrigation as rains provided necessary water for the plants. Similarly, unlock 1.0 in India coincided with the time of the beginning of the annual harvest of cardamom. However, as there were very few or no migrant workers to perform large scale harvest, the first harvest was delayed in most medium and large plantations. The planter Karunakaran took up the challenge by employing Tamils from nearby towns within Idukki district and from bordering Theni district of Tamil Nadu. The temporary Tamil labourers travelled every day from their homes to plantations and return in vans and jeeps, and planters mostly paid the cost of their travel. The interviews of the temporary Tamil workers uncovered that most of them are people who either lost their jobs due to lockdown and a few are youth desiring to earn from the available opportunity. Temporary Tamil workers also narrated that they are transported to plantations by a Kangani (like an agent).

The interview with a Kangani named Raju operating in Shanthanpara and Petthotty villages of Idukki informed that payments are mostly between planters and Kanganis. The Kanganis pay temporary workers and drivers after taking a cut for themselves. For some years, the daily wage of migrant workers are around three hundred rupees, and permanent workers are paid five hundred rupees. But the temporary Tamil workers are paid five hundred and fifty for each person. As mentioned before, most of the temporary Tamil workers are unskilled, and there lacked necessary less time to train them for carefully pluck ripened cardamom cloves from the plants. Thus, many planters and a local cardamom buyer Karim of Estate Poopara reported that upon drying the weight of the cloves reduced rapidly as unskilled labourers plucked more unripe cardamom cloves during harvest. The planter Shaji of Pethotty informed that unskilled temporary labor hired during the emergency as slower in harvesting and many of the ripe cloves began to shed the seeds. The heavy rains and lack of labor force for weeding resulted in the decay of several plants in various plantations. Similarly, the difficulty in spraying pesticides resulted in cardamom cloves developing rough texture due to pest infest.

Regardless of the drawbacks, planters widely employed temporary labor force supplied by kanganis as they were 
crucial in carrying headloads of cardamom filled bags from plantations inaccessible by vehicles. Few Cardamom growers like Shaji of Pethotty undertook a different challenge by bringing back the migrant workers from Madhya Pradesh in a private bus after obtaining permission from the government. Subsequently, the health ministry of Kerala directed the migrant workers who returned to high ranges in various private transport to follow two weeks of compulsory quarantine. The cost of transportation and quarantine was born by the planters. However, there were instances where migrant workers brought by a particular planter by baring all expenses escaping to work for another planter who guarantees higher wage. Such situations resulted in police personnel involving in the internal matters of the plantation.

In various small plantations, the members of the family, including children, contributed to the harvest. Many of small-scale cardamom growers became depended entirely on the sale of cardamom as the government suspended other entrepreneurial opportunities offered by tourism due to lockdown. The global stagnation in the economy due to the COVID-19 pandemic resulted in fall in the price of cardamom cloves. Producers mostly sell the cardamom in auctions or to local buyers who in turn sell to large scale traders. Economic constraints forced many poor planters to sell the cardamom at a much lower price to the local buyers as they needed money to pay kanganis and to pay back in the banks. As the situations were terrible for small planters, many of them sought employment in large plantations as temporary labor to meet the expenses of livelihood.

Many large-scale planters like Shaji and Karunakaran, informed that planters might not even get back the expediated expenditure by selling at low prices in the auction. The flow of cardamom for auctions also reduced as auctions proved non-profitable to many large planters. The small-scale farmers with less quantity of cardamom might not spend so much on transport to sell in the auction; instead, sells to a local buyer for less than the average price at auctions. The local cardamom dealer Kareem of Estate Poopara mentioned that the inflow of cardamom towards buyers reduced as price decreased. Many large-scale planters decided not to sell their produce as the market is not profitable for them. Ajay Kumar, a manager of Haritha Co-operative Cardamom Drying plant located in Estate Poopara, informed that despite drying and processing of tons of cardamom this year the planters are yet to pay for their services. The owners of small and medium plantations usually pay the dryers after selling their produce. As fewer quantities of cardamom are sold at auctions and local buyers that offer less price the dryers remain unpaid for longer durations.

Neither the Government of India nor Government of the State of Kerala has so far offered Minimum Support Price (MSP) for cardamom crops. In a plantation perspective, the value of the produce and the expenditure for cultivation might determine the relative profitability. Increased labor cost and expenses of fertilizers and pesticides, together with the decrease in the price of cardamom precipitously, reduce the annual profit of planters. Despite lockdown and stagnation of tourism, a kilogram of first quality cardamom in a retail shop costs around four thousand rupees; meanwhile, the average price at an auction turns out as thousand five hundred rupees per kilogram. The local buyers offer less than the average auction price for the planters.

After completing all four annual harvests of cardamom, the planters with plants older than ten years initiate replanting of crops. The exercise of massive scale replanting is usually carried out by allocating specific areas to each migrant worker and are regularly instructed by managers of plantations or experienced kanganis hired by planters. The low relative profitability due to migrant labor crisis, expensive unskilled labor, and fall in price led many planters to avoid routine replantation. The replantation of large plantations is an elaborate exercise; therefore, it requires a skilled and committed labor force to generate the most satisfactory results. Most of the planters avoid taking the risk of replanting with unskilled labor who emerged out of situations created by COVID-19 pandemic lockdown.

\section{CONCLUSION}

Personal conflict should be kept aside, especially during a pandemic. If the company has to announce layoffs, it would be a good idea to tell workers why the company is taking the actions. For instance, if layoffs are genuine to protect the company's bottom line, it is to be explained that to fire workers along with the reason for why certain departments or positions were hit, so they do not feel they were singled out. There is a saying that a good employee is an asset to your company, so the companies should try to be a good employer and make a good employee for the company. Employer and employee are two sides of the same coin and must sail together during a difficult storm like that of the COVID-19 pandemic. Businesses leaders can take this time to reflect, restrategize business plans, and brainstorm the new market to explore after the pandemic. With grit, resilience, and perseverance, small businesses will emerge stronger than before. 


\section{Conflict of Interests}

The author declares that he has no conflict of interest.

\section{ACKNOWLEDGMENT}

The author expresses sincere gratitude to plantation labourers, managers, owners, commercial dryers, traders, and auctioneers of Idukki.

\section{REFERENCES}

Aiya, V.N. (1906). The Travancore State Manual. Travancore Government Press, Trivandrum.

Anju, S. \& Kumar, N.K. (2020). Scenario Analysis of Cardamom Growers in Cardamom Hill Reserves of Kerala. Journal of Extension Education, 32(1), pp 6468-6470.
Lovatt, H. \& de Jong, P. (1993). Above the Heron's Pool: A Short History of the Peermade Vandiperiyar District of Travancore. British Association for Cemeteries in South Asia, London.

Mathew, L. \& James, P. (2017). Problems and Prospects of Cardamom Cultivation in Idukki District. International Journal of Economics and Management Studies, 4(6), pp 38-46.

Ravindran, P.N. \& Madhusoodanan, K. (2002). Cardamom: The Genus Elettaria. CRC Press, London.

Varghese, P.K. (2007). Economics of Cardamom Cultivation in Kerala. Indian Journal of Agricultural Economics, 62(1), pp 1-14. 